\title{
End coming for misunderstood CMA House
}

I t has been called bland. Even ugly. The rusting steel exterior cladding was an unsightly embarrassment for some staff. It has also been described as refined, meticulously designed and architecturally significant. One thing it has never been is dull.

The Canadian Medical Association House in Ottawa was conceived and built in the late " $60 \mathrm{~s}$, when deals were sealed with handshakes over three-martini lunches. The result, completed in 1970, was straight out of the Mad Men era: a two-storey, 43 000-square-foot, glass and granite structure in then-current architectural styles. Inside, a catwalk to the board rooms loomed over reception, and a smoker's lounge featured startling blue sculptured dividers. The catwalk and lounge are long gone, along with the orange shag carpet and period furniture, but the building itself has served the association for 47 years.

An adjoining tower was built in 1993 to accommodate the growing number of staff. But now both buildings have reached their best-before dates and are slated for decommissioning in July, when anything recyclable or salvageable will be removed. Then, come fall, demolition. No one seems to be lamenting the tower; it has long been plagued with mechanical problems and needs new windows - a pricey undertaking given the glass exterior. But the demise of the original structure, some experts say, will be a true loss.

"It's an unappreciated gem of Canadian architecture," said New Brunswick architect and historian John Leroux.

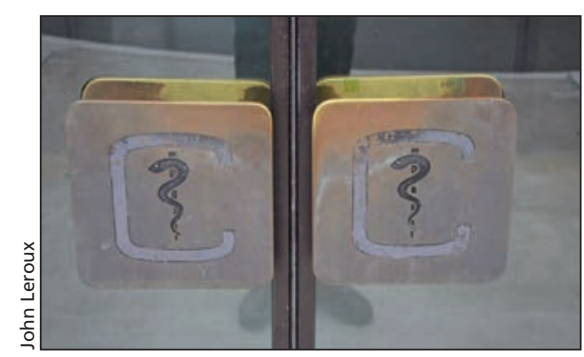

The bronze door handles are high quality, iconic elements that should be used in the new building, said architect Leroux.

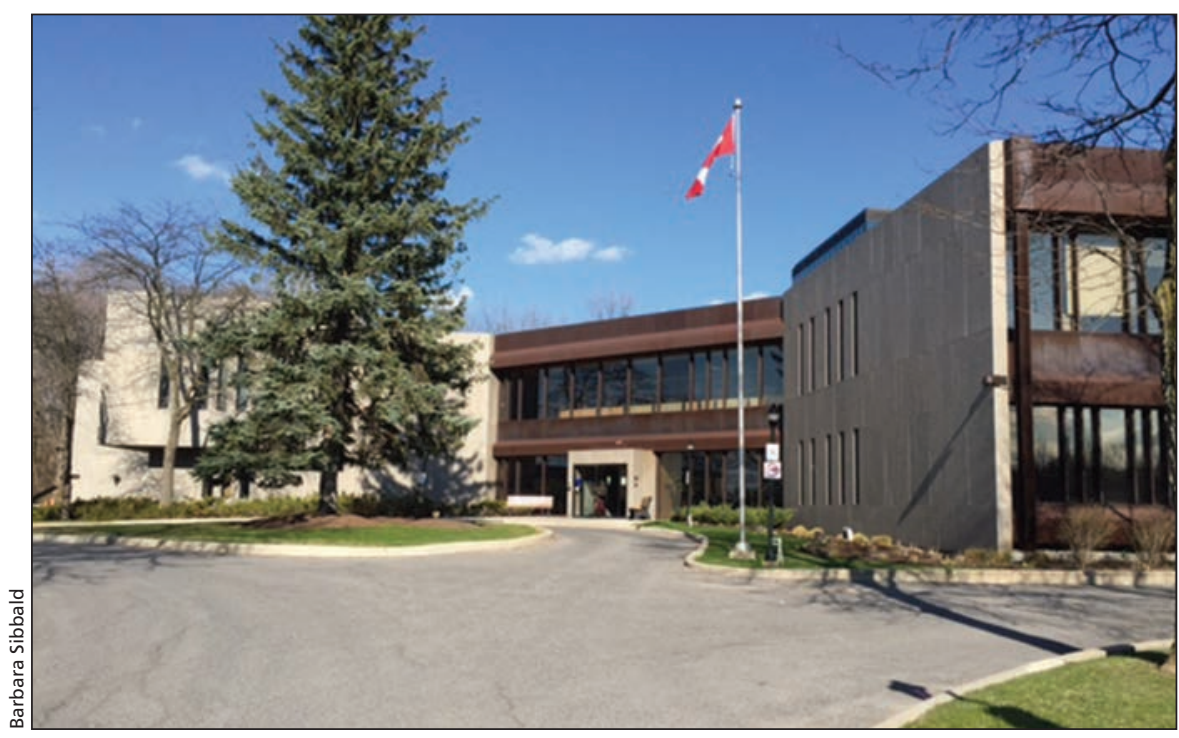

The 1970 CMA House, designed to reflect a "balance between respect for tradition and a strong emphasis on the future," is a gem of Canadian architecture, said one expert.

Ottawa urban history writer Robert Smythe, echoes that assessment: "The CMA headquarters is an exceptionally refined but robust late-1960s building using high-quality materials, and it is deeply regrettable that a decision has been made to demolish it."

Architectural historian Professor Annmarie Adams of McGill University, who specializes in health architecture, agrees that the building has gravitas in the tradition of other medical association buildings. These include the British Medical Association (BMA) House in London's Tavistock Square, designed in 1925 by Sir Edwin Lutyens, and BMA's headquarters in Sydney, Australia, a "splendid" 1930 Art Deco tower, with statuary that includes seated knights with caduceus shields and koalas.

"Both these buildings show physicians as men of culture, and their associations as sophisticated architectural clients capable of guiding powerful building projects," said Adams.

CMA's 1970 building added a modern twist to this tradition. "It's swanky, suburban, part Don Draper, part Mike Brady," said Adams. "It goes with electric meat knives and gas barbecues. Certainly it gets away from the image of medicine as a place of white tiles and lab coats. This is key."

That decision to demolish the building was based on both structural and functional deficiencies, said CMA Chief Executive Officer Tim Smith. "The costs to renovate were close to, if not more than, tearing down and rebuilding. And the reason [for the demolition] is because the building codes have changed so much."

Smith would not make the consultant's analysis public, but did provide some details. There are leaks in the basement: "Foundation issues for sure." The roof needs replacing, the electrical doesn't meet current code and the windows have condensation inside. Plus the heating, ventilation and air conditioning are below par; the boiler is 20-plus years old.

CMA wants LEED certification (Leadership in Energy and Environmental Design), which requires a green approach from demolition to the functioning building. "There is quite a bit of cost to that in a new build, even more so in an old building in terms of renovation," said Smith.

Smythe, the urban planner, holds the opinion that, "Whatever green features are being contemplated will be more 
than negated by committing tonnes of pulverized building material to landfill."

In addition to being structurally flawed, the building has functional limitations, said Smith. CMA wants an openconcept office with clear sight lines and lots of light. The present building has inner walls containing heating, ventilation and electrical that can't be moved, said Smith.

As to its architectural significance, Smith said CMA has hired Leroux to do photographic documentary and video. CMA also hopes to retain some elements of the old building in the new one. "I actually like the building; it's pretty modern for its time. It's a sad thing, but also a good thing in terms of moving on."

\section{The original plan}

The building nearly didn't happen at all. In the 1960s, CMA was based at $150 \mathrm{St}$. George St. in Toronto and looking to expand in that city. They even commissioned two plans. But after a raucous debate at CMA General Council on June 10,1967 , the decision was made, with a vote of 111-55, to relocate to Ottawa. The year before, nationwide medicare had been introduced; CMA needed to be where the action was. It helped too, that Ottawa was already home to several national medical groups.

CMA's intention was to construct a headquarters that "reflects the basic outlook of the Association; a balance between respect for tradition and a strong emphasis on the future" (CMAJ 1970; 103:579).

The traditional aspect began with the natural beauty of its site: three acres of forest and streams, visible through the



The original board room was apparently designed for men only. The long, linear light fixture over the table was later thrown out. "It's too bad because if it had been left, it would be quite appreciated now," said Leroux. building's nearly continuous windows.

"It was a lovely backyard," said

Ron Bannerman, one of two original employees at MD Management, CMA's financial subsidiary, back in 1971. "The ground was undulating, and there was an arching wooden bridge over the stream. Wedding parties came there on weekends to get their pictures taken. There were also fox, partridge, wild turkey, even the odd deer."

The building materials were also from nature: Canadian Shield quartzlike brown and grey granite, bronze and steel, which lent the building permanence, stability and strength.

The site was purchased from the National Capital Commission (NCC) for $\$ 75000$. According to Smythe, the building is "a landmark that forms a part of the [NCC's] planning for Ottawa. This section of Alta Vista Drive was seen as an appropriate location for important national institutions." CMA was the first. "Its design excellence has

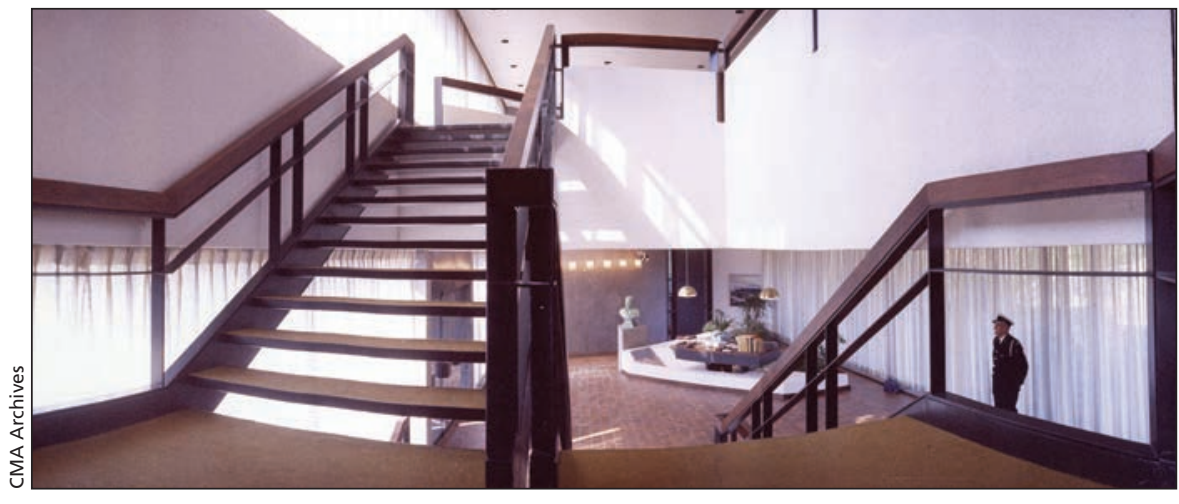

The original staircase led to executive offices that featured exotic wood, including black American walnut. In 1993, this staircase was replaced with an elevator, and a triangleshaped staircase was built in the southwest corner of the reception area.

never been equalled by the subsequent buildings in that sector."

CMA hired a leading Toronto architectural firm, Webb Zerafa Menkes Housden (now WZMH, designers of the CN Tower and Toronto's Royal Bank Plaza). Their innovative design and use of materials helped to establish the reputation of the architect Boris Zerafa (1933-2002). Duncan Green, CMA's consultant architect during the 1960s construction, said Zerafa would later become "the finest architect in Canada. He cut his teeth on this building." Green thinks the building should be designated a Zerafa monument. "They should dismantle and resurrect somewhere. It's a beautiful, beautiful building."

"I'm shocked to hear it's being demolished. It's too good to be gotten rid of."

CMA House uniquely melds two distinct architectural styles. The back, in particular, shows the influence of International style, which was most commonly seen in the sleek steel and glass skyscrapers from the 1940s to early 1960s. But the front, with its raw granite and Cor-Ten steel, is very much Brutalism architecture, which has a raw, heavier, denser materiality.

"By 1970, the International style was giving way to Brutalism, and so the CMA House is a very unique and interesting transitional example of this shift," said Leroux.

Then-Governor General Roland Michener laid the cornerstone on Sept. 20, 1968.

Construction was supposed to be completed by the following summer, but took longer than expected due to strikes, delivery screw-ups and delay in 


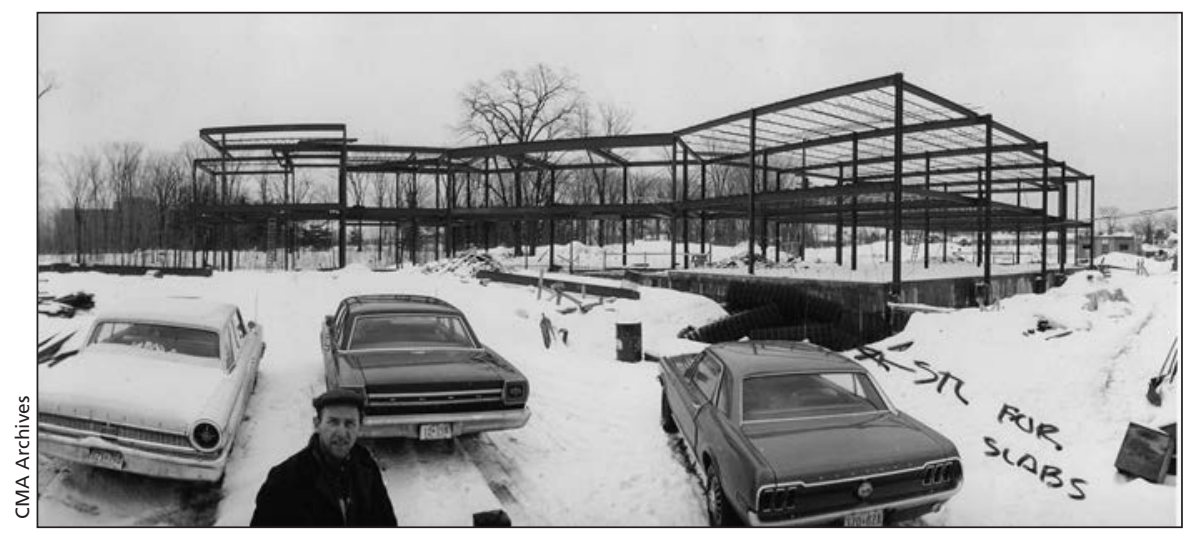

Most CMA staff left Toronto in 1969 after their building was sold. They were temporarily housed in Ottawa in a church basement and an auditorium until the new building was ready.

Ontario Municipal Board approval.

The building was completed by the summer of 1970 and substantially under budget: priced at $\$ 1414900$, it came in at $\$ 1108736$. That included $\$ 146000$ from members, provinces and affiliates for finishings and furnishings; among itemized items are 71 ashtrays for $\$ 995.50$. The building was officially opened with a scalpel across a ribbon on Oct. 2, 1970, by CMA's oldest living past president, Dr. DA Graham.

Importantly, the building was among the first in Canada to use Cor-Ten steel, a new material featured prominently in one of America's greatest post-war office buildings, the John Deere Headquarters (1964) in Illinois. Normal steel rusts through if left exposed; Cor-Ten is treated so that it rusts, turns red or plum, then stops rusting. "If I had to say one connection that gives this building

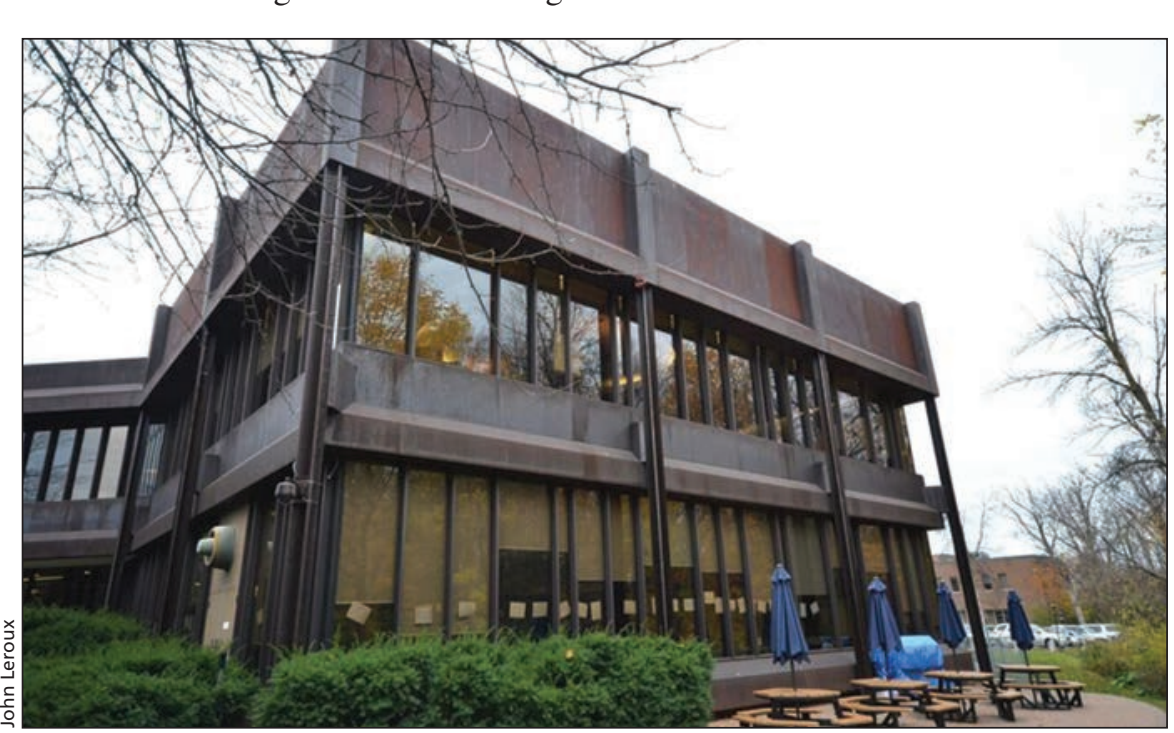

The east side of the building features varying widths of mullions and Cor-Ten cladding, reminiscent of the John Deere building.
The building was slated to meet the association's needs for 20 years, so initially space was leased to tenants. Back then, there were 22000 members; today there are 82000 . The number of CMA staff has grown from 28 to 90 , plus another 82 at its new for-profit subsidiary, Joule. MD Financial Management, meanwhile, has grown from two employees to nearly 1600 across Canada.

By 1984, the building was overcrowded and a two-storey extension (18 000 square feet) was built to the south of the original. Three more stories were added in 1993. And in 2001, MD opened its own building across the street, where some 600 people now work.

Deere building, because ... it really had an enormous effect, and this is based on that building," says Leroux.

But Cor-Ten wasn't appreciated by everyone. Bannerman remembers people saying to him, "Oh, you work in that rusty building on Alta Vista. When are you going to paint it? I was embarrassed [about the building]."

Unquestionably, though, it was thoughtfully constructed. "They calculated where every single piece of stone went, the patterning of the windows and the stone," said Leroux. "Nothing is random. It's extremely well built." For example, on the back, the vertical mullions [vertical bars between panes of glass] are all different widths. "They really play, almost like music," said Leroux. "There's a real intonation." Today, the windows would all be the same size.

\section{New plans}

"In 2017, it would be nice to have a longer term vision for the CMA and we need a building that will support that," said CMA's Smith.

Chmiel architects won the request for proposals, which specified a building between 30000 and 50000 square feet to accommodate 200 people with some potential for growth. The request for proposal is not public, said Smith. Chmiel's final plans are due in May 2017.

Initially, CMA had hoped to have the building ready for its 150th anniversary in October 2017; now they're aiming for early 2018. "One thing I've learned is there are always surprises, always stuff that comes up," said Smith.

There will undoubtedly be celebrations galore when the new building does open, but some will continue to lament what has been lost.

"I couldn't believe it when someone said they were going to pull it down," said Gillian Pancirov, a long-time editor at the Canadian Journal of Surgery who moved from Toronto to the new building. "It seems like it's been there forever. It was a good spot to work. I loved it! All those big windows."

"This building has some real weight that no one knew about," said Leroux. He likens it to a bank: a building with permanence and gravitas. "It is very, very important and extremely well done; a remarkable Canadian work of architecture from the late 1960s." - Barbara Sibbald, $C M A J$

CMAJ 2016. DOI:10.1503/cmaj.109-5279 